Am. J. Trop. Med. Hyg., 72(6), 2005, pp. 694-701

Copyright (C) 2005 by The American Society of Tropical Medicine and Hygiene

\title{
MEASURING ALLELIC HETEROGENEITY IN PLASMODIUM FALCIPARUM BY A HETERODUPLEX TRACKING ASSAY
}

\author{
WARUNEE NGRENNGARMLERT,* JESSE J. KWIEK,* DEBORAH D. KAMWENDO, KIMBERLY RITOLA, \\ RONALD SWANSTROM, CHANSUDA WONGSRICHANALAI, R. SCOTT MILLER, WANIDA ITTARAT, AND \\ STEVEN R. MESHNICK \\ Department of Clinical Microscopy, Faculty of Medical Technology, Mahidol University, Bangkok, Thailand; Departments of \\ Epidemiology, Microbiology and Immunology, and Center for AIDS Research, University of North Carolina, Chapel Hill, North \\ Carolina; Department of Epidemiology, University of Michigan School of Public Health, Ann Arbor, Michigan; Department of \\ Immunology and Medicine, Armed Forces Research Institute of Medical Sciences, Bangkok, Thailand
}

\begin{abstract}
We developed a novel Plasmodium falciparum genotyping strategy based on the heteroduplex tracking assay (HTA) method commonly used to genotype viruses. Because it can detect both sequence and size polymorphisms, we hypothesized that HTA is more sensitive than current methods. To test this hypothesis, we compared the ability of HTA and a nested polymerase chain reaction (PCR) to detect genetic diversity in 17 Thai samples. The HTA detected more MSP1 sequence variants in eight isolates (47\%), less sequence variants in three isolates (18\%), and an equal number of sequence variants in six isolates (35\%), suggesting that HTA is equal to or more sensitive than the nested PCR. This study is a proof of concept that HTA is a sensitive allelic discrimination method able to determine genetic diversity in $P$. falciparum and warrants its use in studies of antimalarial drug efficacy.
\end{abstract}

\section{INTRODUCTION}

Plasmodium falciparum, the most virulent of the four parasite species causing human malaria, exhibits significant genetic diversity. This diversity is particularly striking in targets of host immunity such as merozoite surface protein 1 (PfMSP1), which encodes a 190-kD membrane-anchored protein that displays both size and nucleotide polymorphisms. ${ }^{1-4}$ Due to its high sequence divergence, the block 2 region of $P f M S P 1$ is an ideal locus to delineate multiplicity of infection. Several polymerase chain reaction (PCR) methods have already been developed that exploit PfMSP1 diversity, including the following: nested PCR, single-strand conformation polymorphism (SSCP), restriction fragment length polymorphism (RFLP), and direct DNA sequencing (reviewed by Snounou and Beck ${ }^{5}$ ). Of these methods, the nested PCR is used most often, and although very sensitive in its ability to detect size polymorphisms, it has three main shortcomings: an inability to detect DNA sequence polymorphisms, a diminished sensitivity at low parasite densities, and poor resolution at high parasitemias. ${ }^{6}$

Capable of resolving multiple nucleotide sequences in a single sample, the heteroduplex tracking assay (HTA) has been used extensively to genotype human immunodeficiency virus (HIV) and other viruses. ${ }^{7-9}$ When the HTA is used, a radiolabeled DNA probe is annealed to a PCR-amplified polymorphic sequence, and double-strand DNA duplexes are formed with the complementary sequence. Perfect complements, termed homoduplexes, migrate according to size on a native polyacrylamide gel, while partial DNA duplexes, such as those caused by clustered base pair mismatches and/or size polymorphisms, migrate more slowly. Because the assay is sensitive to the conformation of the DNA, which is determined by the genotype, each HTA band represents a distinct genetic variant and the overall banding pattern is a fingerprint of the infection.

In this report, we describe a novel PfMSP1 HTA able to discern genetically distinct sequence variants of $P$. falciparum. The ability of this assay to distinguish basepair substitutions

*These authors contributed equally to this article. as well as size polymorphisms introduces a novel, sequencesensitive technique that will augment our ability to distinguish $P$. falciparum recrudescence from reinfection.

\section{MATERIALS AND METHODS}

Study samples. Informed consent, as approved by the ethics committees of the University of North Carolina, the Thai Ministry of Public Health, or the Malawi College of Medicine/ Ministry of Health, was obtained from all participants in this research. The AF patient samples are from a cross-sectional study in southeast Asia reported by Pickard and others. ${ }^{10}$ The GR samples originated from a study in Tak Province on the western border of Thailand; this region is considered an area of low malaria transmission, with an estimated entomologic inoculation rate of 1-2 infective bites per person per year (Miller RS, unpublished data). In the GR study, patients with $P$. falciparum malaria were treated with mefloquine, and those found with recurrent $P$. falciparum infections within 42 days of enrollment were re-treated. Paired admission and recurrent infection samples were obtained and the parasitemia per microliter was quantitated by light microscopy of Geimsastained thick blood smears. Genomic DNA from these samples was extracted as previously described. ${ }^{10}$ The MHP1452 probe is from a malaria-positive, pregnant woman in the Malaria and HIV in Pregnancy study reported by Mwapasa and others. ${ }^{11}$

Amplification of the PfMSPI block 2 by PCR. Amplification of $P$. falciparum DNA was performed with a Peltier thermal cycler (MJ Research, Waltham, MA) in a final volume of $50 \mu \mathrm{L}$. Reactions consisted of $2 \mu \mathrm{L}$ of parasite DNA in $1 \times$ PCR buffer, $1.5 \mathrm{mM} \mathrm{MgCl}, 125 \mu \mathrm{M}$ of each dNTP, 1 unit of HotStarTaq DNA polymerase (Qiagen, Valencia, CA), and $250 \mathrm{nM}$ of forward and reverse primers (modified from Kimura and others ${ }^{12}$; C1F: 5'-GAAGATGCAGTATTGACAGG-3', and C3R: 5'-TGATTGGTTAAATCAAAGAG$\left.3^{\prime}\right)$. The amplification program consisted of preheating to $95^{\circ} \mathrm{C}$ for 15 minutes, followed by 24 cycles at $94^{\circ} \mathrm{C}$ for 1 minute, $50^{\circ} \mathrm{C}$ for 2 minutes, and $72^{\circ} \mathrm{C}$ for 2 minutes. The PCR products were subjected to electrophoresis on $1.2 \%$ agarose gels, visualized under ultraviolet light after staining with 
ethidium bromide, and sized against a 100-basepair molecular weight marker (Promega, Madison, WI). Successful amplification resulted in products of approximately 300 basepairs. All PCRs were done in duplicate to ensure reproducible sampling of the sequence variants.

Plasmids and probes. The HTA probes were constructed by amplifying block 2 of PfMSP1 from three Thai samples (AF22, AF42, and AF63), and one African sample (MHP1452). The PCR products were blunt-end cloned into the pT7Blue vector using the Perfectly Blunt cloning kit (Novagen, Inc., Madison, WI). Plasmid DNA was amplified according to the manufacturer's instructions and purified with the Wizard Plus SV miniprep DNA Purification System (Promega).

Ten micrograms of the PfMSP1 block 2-pT7Blue construct was digested with $\mathrm{Bam} \mathrm{HI}$ at $37^{\circ} \mathrm{C}$ for one hour and then end labeled in the same buffer by filling in the Bam HI overhang for 15 minutes at $25^{\circ} \mathrm{C}$ using $1 \times$ Eco pol buffer (New England Biolabs, Beverly, MA), $10 \mathrm{mM}$ dithiothreitol, $50 \mu \mathrm{M}$ dGTP, $50 \mu \mathrm{Ci}\left(\alpha^{-}{ }^{35} \mathrm{~S}\right)$ of dATP $(1,250 \mathrm{Ci} / \mathrm{mmol}$; ICN, Irvine, CA $)$, and 10 units of Klenow fragment. The reaction was stopped by the addition of EDTA ( $10 \mathrm{mM}$ final concentration) and heat inactivation at $75^{\circ} \mathrm{C}$ for 15 minutes. The radiolabeled probe was released from the vector by digestion with Pst I at $37^{\circ} \mathrm{C}$ for one hour, and the probe was separated from the vector after electrophoresis on an agarose gel. The radiolabeled insert was excised from the gel and purified with the QIAquick gel extraction kit (Qiagen).

Heteroduplex tracking assay (PfMSP1 HTA). The heteroduplex annealing reaction mixtures consisted of $5 \mu \mathrm{L}$ of PCRamplified block 2 of PfMSP1 from patient samples or $5 \mu \mathrm{L}$ of gel-purified amplicons from the plasmid DNA controls, $1 \mu \mathrm{L}$ of $10 \times$ annealing buffer $(1 \mathrm{M} \mathrm{NaCl}, 100 \mathrm{mM}$ Tris- $\mathrm{HCl}, \mathrm{pH} 7.5$, $20 \mathrm{mM}$ EDTA), $0.1 \mu \mathrm{M}$ of $\mathrm{C} 1 \mathrm{~F}$ primer, and $1 \mu \mathrm{L}$ of ${ }^{35} \mathrm{~S}$ labeled probe in a total volume of $10 \mu \mathrm{L}$. The $\mathrm{C} 1 \mathrm{~F}$ primers were added to the annealing reaction to bind excess probe. ${ }^{8}$ The DNA duplexes were denatured at $95^{\circ} \mathrm{C}$ for 2 minutes followed by annealing at $25^{\circ} \mathrm{C}$ for 5 minutes. Heteroduplexes were mixed with $6 \times$ DNA loading buffer (Promega) and separated by electrophoresis on a $6 \%$ polyacrylamide gel (acrylamide:bisacrylamide $=37.5: 1$ ) in $1 \times$ Tris-borate-EDTA buffer at $17 \mathrm{~mA}$ per gel for 4.5 hours. The gels were dried onto filter paper (Whatman, Florham Park, NJ) and exposed to BioMax MR x-ray film (Eastman Kodak, Rochester, NY) for approximately 18 hours at $25^{\circ} \mathrm{C}$. Alternatively, for quantitative data, the dried gels were exposed to a phorphorimager screen for two days and the band intensities were quantitated according to the manufacturer's instructions (Molecular Dynamics, Sunnyvale, CA).

Figure 1 outlines the potential probe-sample interactions observed in HTA experiments; the probe sequence is in bold type and the sample, or unknown sequence, is in regular type. Single-stranded probes, as shown in Figure 1A, are unordered and flexible and therefore migrate more slowly than probes annealed to their complement (homoduplexes) (Figure 1B). When the probe and sample are not complementary, one of three structural distortions occurs after annealing: 1) clustered basepair mismatches cause a bulge between the probe and the sample (Figure 1C), 2) deletions in the sample sequence cause the probe to loop out (Figure 1D), or, 3) insertions in the sample sequence are looped out (Figure 1E). Any one of the latter three complexes, either alone or in combi-
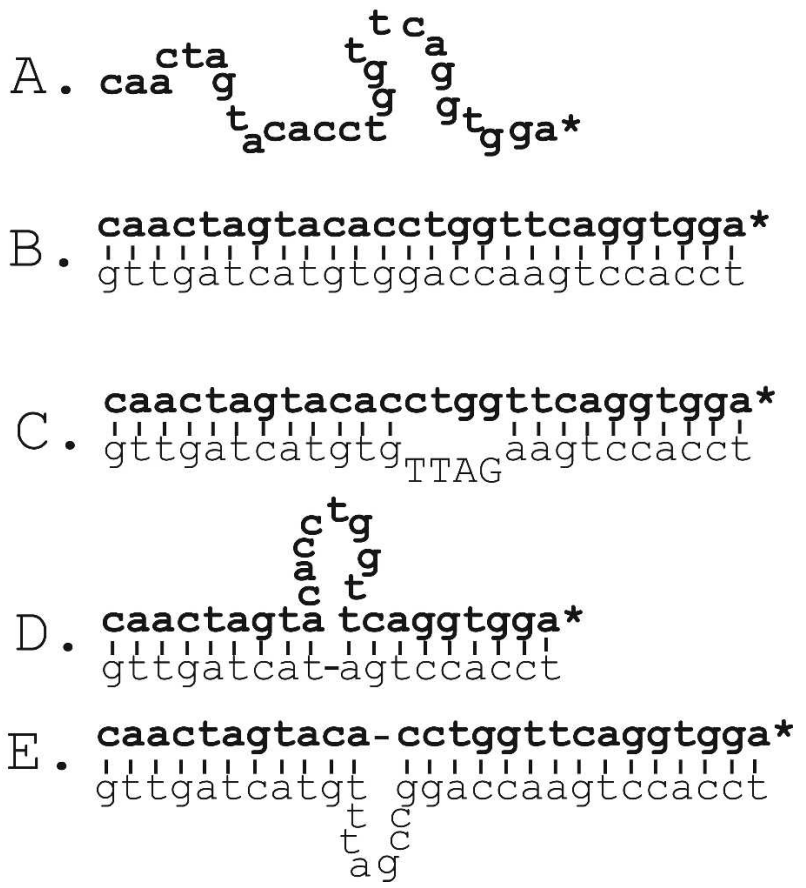

FIGURE 1. Principle of the heteroduplex tracking assay. Single stranded probes (bold) are radiolabeled and annealed to Plasmodium falciparum merozoite surface protein 1 amplicons from patient isolates as described in the Materials and Methods. Radiolabeled probes migrate on the gel alone as in $\mathbf{A}$, a single-stranded probe, or in complexes with the complementary DNA, such as B, homoduplexes, $\mathbf{C}$, heteroduplexes with clustered base pair mismatches, D, heteroduplexes with sample deletion(s), and $\mathbf{E}$, heteroduplexes with sample insertion(s).

nation, retards the migration of the probe-sample complexes compared with the homoduplexes. ${ }^{13}$

HTA-based sequence diversity. The HTA results are the minimum number of sequences counted by two independent investigators blinded to the nested PCR results. Only major HTA bands, which contain approximately $10 \%$ or greater of the total signal in an individual lane, were considered true HTA heteroduplexes. Bands with less than $10 \%$ of the total signal, or bands common to all lanes (which could represent either true minority sequence variants or PCR artifacts) were not counted; exclusion of minor bands could potentially bias this study towards an underreporting of sequence diversity.

Sequencing and alignment of DNA. The DNA was sequenced at the University of North Carolina-Chapel Hill Automated DNA Sequencing Facility on a 3100 Genetic Analyzer (Applied Biosystems, Foster City, CA) using the ABI PRISM $^{\mathrm{TM}}$ BigDye $^{\mathrm{TM}}$ Terminator Cycle Sequencing Ready Reaction Kit FS with AmpliTaq DNA Polymerase, (Applied Biosystems). Sequencing was performed from both directions using the $\mathrm{C} 1 \mathrm{~F}$ and $\mathrm{C} 3 \mathrm{R}$ primers. The DNA sequences were aligned with Clustal-X (http://www2.ebi.ac.uk/clustalw/) and displayed using GeneDoc (http://www.psc.edu/biomed/ genedoc/).

Nested PCR for genotyping $\boldsymbol{P}$. falciparum. Seventeen AF samples were genotyped for $M S P 1, M S P 2$, and glutamaterich protein $(G L U R P)$ as reported by Pickard and others ${ }^{10}$ using the methodology reported by Kamwendo and others ${ }^{14}$ and Snounou and others. ${ }^{15}$ Briefly, PfMSP1 block 2, the central polymorphic region of $M S P 2$, and GLURP were PCR 
A.

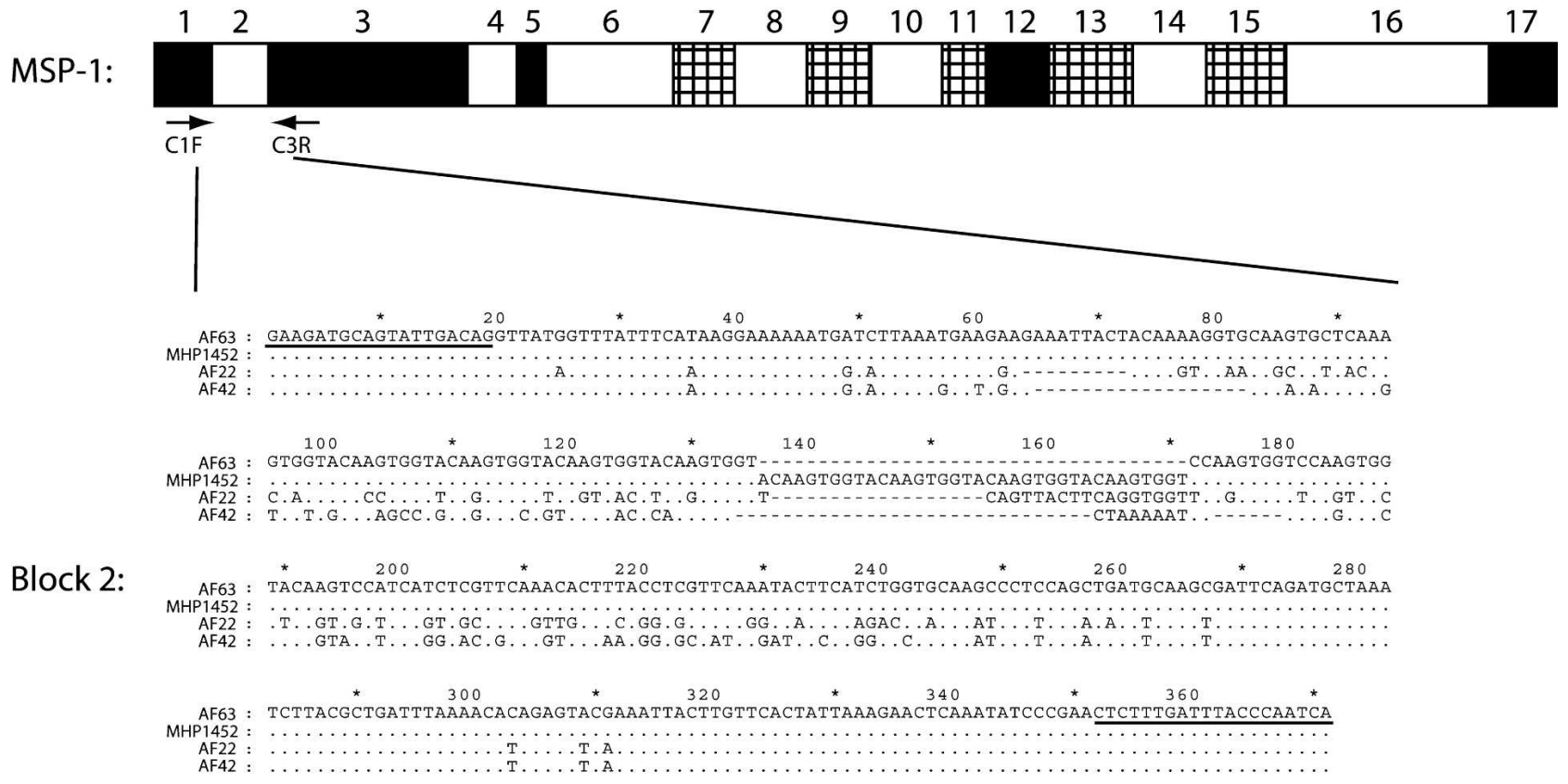

B.
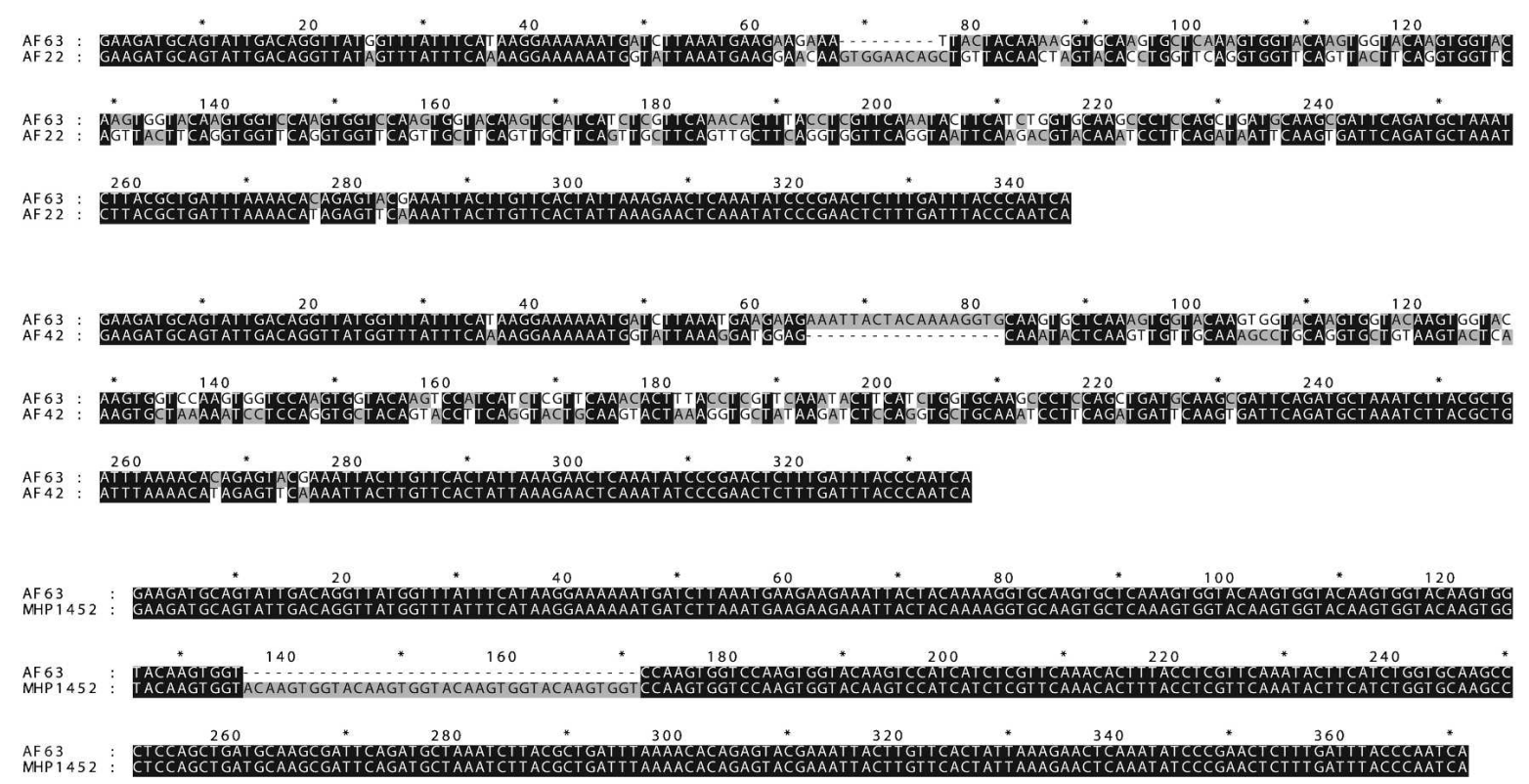

Figure 2. A, Basic structure of the Plasmodium falciparum merozoite surface protein 1 (PfMSP1) gene (adapted from Tanabe and others ${ }^{1}$ ). Conserved, semiconserved, and variable blocks of the gene are shown as closed, hatched, and open blocks, respectively. Shown below the PfMSP1 schematic is a multiple sequence alignment of the PfMSP1 block 2 clones used for the PfMSP1 heteroduplex tracking assay. All sequences are pairwise aligned with the AF63 clone; conserved nucleotides are shown as dots and deletions are shown as dashes. Underlined nucleotides correspond to the primers $\mathrm{C} 1 \mathrm{~F}$ and $\mathrm{C} 3 \mathrm{R}$ used to amplify block 2 by a polymerase chain reaction. B, Individual pairwise alignments of AF63 with AF22, AF42, and MHP1452. Black shading represent conserved nucleotides, gray regions represent nucleotide mismatches, and dashes represent nucleotide insertions or deletions.

amplified using primers specific for the three known MSP1 allelic families (K1, MAD20, and RO33), the known MSP2 families (IC and FC27) or GLURP. Amplicons from the secondary (nested) PCR were resolved by electrophoresis on an agarose gel and size polymorphisms were noted. Nested PCRs and the interpretation of their results were conducted by an investigator (DDK) masked to the HTA results. ${ }^{10,15}$

\section{RESULTS}

Development of the PfMSP1 HTA. To generate molecular probes that established different $P f M S P 1$ sequence variants, the PfMSP1 block 2 region of four samples (AF22, AF42, AF63, and MHP1452) were PCR amplified and cloned into pT7Blue vector. The PCR amplicons from these clones were 
344, 317, 335, and 371 basepairs (AF22, AF42, AF63, and MHP1452, respectively). Figure 2 shows the DNA sequence alignment of these amplicons and their relationship to the PfMSP1 gene. Sequence differences between these probes, as determined by pairwise alignment to AF63, are as follows: AF22 has 1 insertion of 9 nucleotides and 75 basepair mismatches, AF42 has 1 deletion of 18 nucleotides and 68 mismatches, and MHP1452 has 1 insertion of 36 nucleotides and no base-pair mismatches (Figure 2B). Comparison of the AF22, AF42, AF63, and MHP1452 sequences to PfMSP1 block 2 subtypes $\mathrm{K} 1$, MAD20 and RO33 suggests that AF63 and MHP1452 are allelic subtype K1, AF22 is MAD20, and AF42 is subtype RO33 (date not shown). However, these PfMSP1 family assignments should be interpreted with caution because the repetitive nature of $P f M S P 1$ makes estimates of genetic variation between PfMSP1 alleles difficult to quantify. ${ }^{16,17}$

Verification of the PfMSP1 HTA. By mixing a radiolabeled AF63 probe with equal amounts of AF22 (MAD20), AF42 (RO33), or MHP1452 (K1) amplicons, we determined the ability of the AF63 probe to bind to different PfMSP1 subtypes. The K1 (AF63) probe can distinguish between all three PfMSP1 families, as is evident by the three bands with unique mobilities (Figure 3, lanes 2-4). The band of the AF42 (RO33) and AF22 (MAD20) heteroduplexes are much sharper compared with the MHP1452 (K1) heteroduplex; the diffuse signal of the AF63-MHP1452 complex suggests that it is an unstable, dynamic heteroduplex. Quantitation of the area of the heteroduplex bands determined that the signal of the diffuse MHP1452 complex is not equivalent to the signal of the tighter AF22 or AF42 signals, lending further support

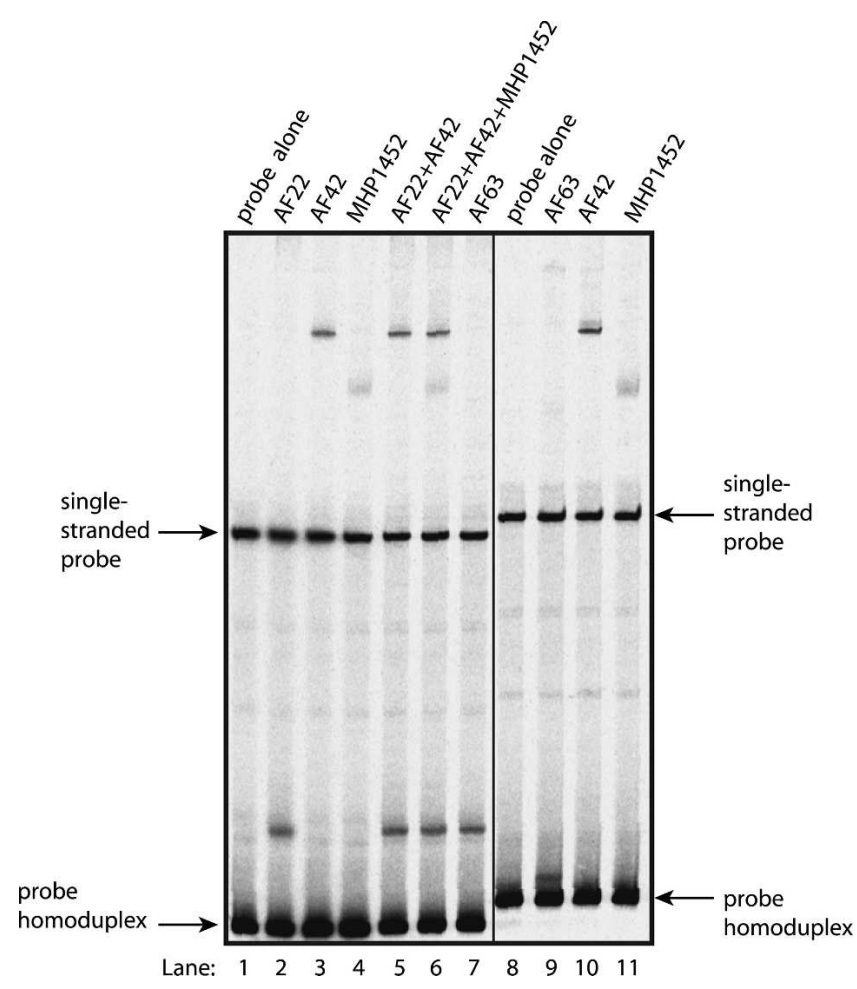

FIGURE 3. Autoradiogram of Plasmodium falciparum merozoite surface protein 1 heteroduplex tracking assay analysis using the AF63 probe (lanes 1-7) and the AF22 probe (lanes 8-11). Probes were annealed with equal amounts of polymerase chain reaction products amplified from AF22, AF42, AF63, and MHP1452 plasmids. to the notion that the AF63 probe does not anneal tightly to the MHP1452 sequence (date not shown).

To test the ability of the AF63 probe to detect sequences similar to itself, we annealed the AF63 amplicon with AF63 probe. As seen in Figure 3, lane 7, this complex does not comigrate with the probe homoduplex; instead, it comigrates to a position similar to the AF22-AF63 heteroduplex, possibly because the AF63 probe is longer than the amplicon. Digestion of the AF63 probe with Nde I, which removes most of the extra nucleotides, caused the AF63 probe/AF63 amplicon complex to comigrate with the probe homoduplex (date not shown). This observation suggests that the AF63 probe can detect PfMSP1 sequence variants that are very similar to the probe sequence. Furthermore, annealing the plasmid-derived amplicons to a radiolabeled AF22 probe yielded HTA migration patterns similar to the AF63 probe (Figure 3, lanes 9-11). These data support the notion that the HTA probes developed within this study are capable of binding to sequence variants from all of the PfMSP1 allelic families.

Next, we investigated the ability of the HTA to probe a mixture of PfMSP1 sequence variants, as would be found in an isolate from a patient with a multiclonal infection. As expected, when AF22 and AF42 block-2 amplicons are mixed and annealed to an AF63 probe, two heteroduplex bands are observed (Figure 3, lane 5). Furthermore, a mixture of AF22, AF42, and MHP1452 annealed to the AF63 probe yields three heteroduplex bands (Figure 3, lane 6). These results show that the HTA using a single probe can simultaneously detect multiclonal and multifamily infections.

To determine if one HTA probe is more sensitive than the others in the detection of PfMSP1 sequence variants, $17 \mathrm{AF}$ samples were annealed individually with all four probes. Figure 4 shows the HTA patterns of four representative patient samples. Each of the probes yielded different patterns of major bands, and in some cases the probes identified an unequal number of sequence variants for each sample. However, these differences were not due to assay reproducibility or biased sequence sampling because all samples were PCR amplified in duplicate, and in every case, the HTA pattern was identical between replicates (date not shown). Although no single probe always detected more sequence variants than the others, the AF63 probe most consistently detected the largest number of $P f M S P 1$ sequence variants. Overall, depending on the probe used, between five and seven unique PfMSP1 sequences were detected in the AF study population, which reflects the low malaria transmission of this region.

Next, we compared the sensitivities of the PfMSP1 HTA to the nested PCR in two ways in 17 clinical samples (Figure 5). First, a comparison was made between the number of size variants detected by the PfMSP1 nested PCR alone to the number of sequence variants detected by a single HTA probe (AF63). The HTA detected more sequence variants in 8 (47\%) of 17 isolates, less sequence variants in $3(18 \%)$ of 17 isolates, and an equal number in $6(35 \%)$ of 17 isolates. Second, a nested PCR of PfMSP1, MSP2, and GLURP was compared with HTA using all four probes. Again, the HTA detected more sequence variants in $8(47 \%)$ of 17 isolates, less sequence variants in $3(18 \%)$ of 17 isolates, and an equal number in $6(35 \%)$ of 17 isolates. These results suggest that the HTA is equivalent to or better than the nested PCR in determining the number of $P$. falciparum sequence variants in a patient isolate. 


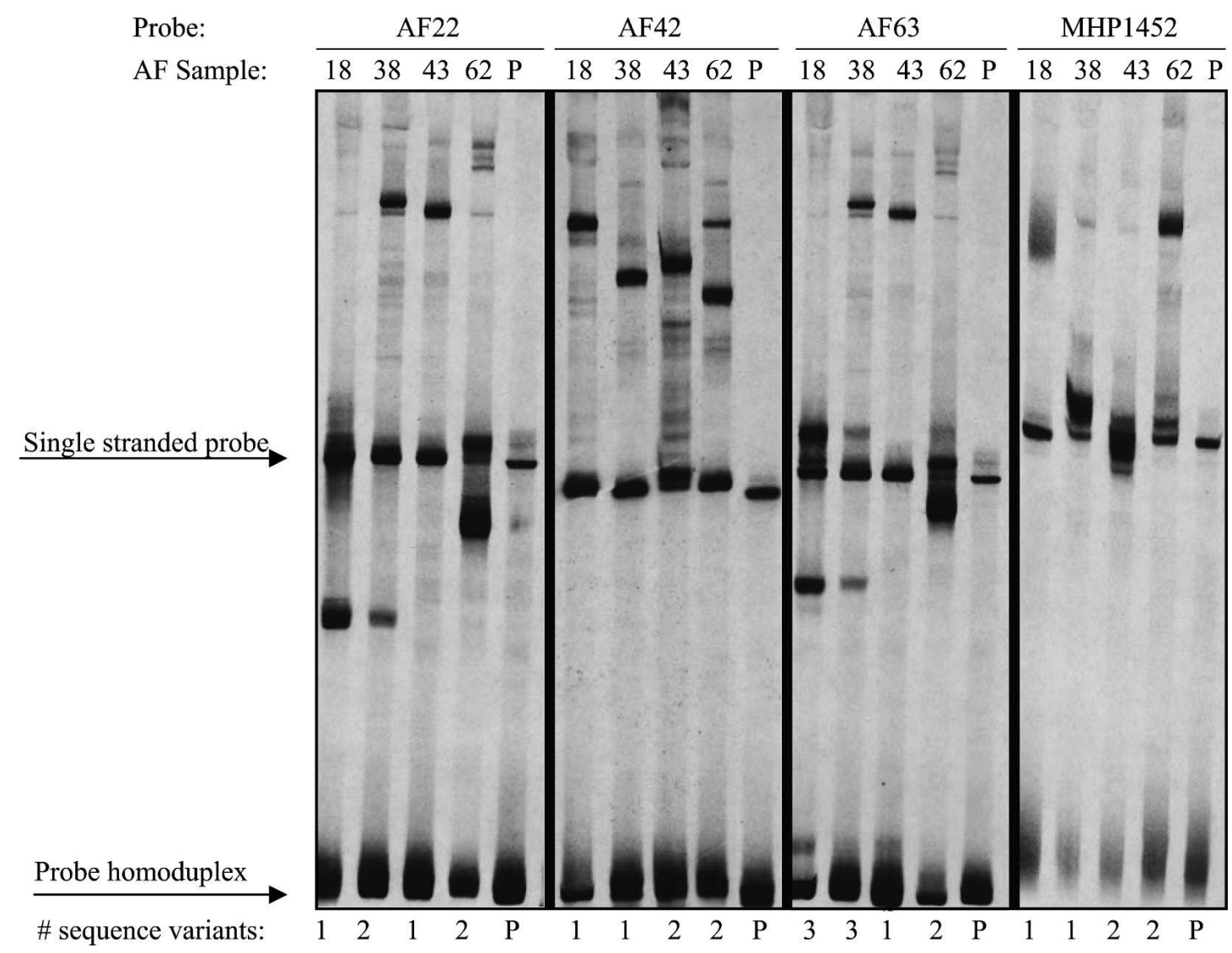

Figure 4. Autoradiogram of Plasmodium falciparum merozoite surface protein 1 heteroduplex tracking assay analysis using probes developed from the AF22, AF42, AF63, and the MHP1452 samples. The probes were annealed with polymerase chain reaction products amplified from four patient isolates (AF18, AF38, AF43, and AF62). Sample number indicates the AF sample number and $\mathrm{P}$ indicates the probe alone lane. The number of sequence variants enumerated per patient sample is listed under each lane.

Application of the PfMSP1 HTA. Finally, the HTA was evaluated for its ability to distinguish a recrudescent $P$. falciparum infection from a new infection. The PfMSP1 block 2 was amplified from seven matched GR admission and recurrent samples. The PCR products were annealed with probe AF63 and the heteroduplex pattern of the parasite infection at the time of admission (labeled A) was compared with that of recurrent parasites (labeled R). As shown in Figure 6, the HTA pattern of four recurrent samples matched or was contained within the pattern of their paired admission samples (GR1, GR4,GR10, and GR27). These infections could represent one of two outcomes: a recrudescence infection from a patient who failed drug treatment, or a reinfection with parasites containing the same compliment of sequence variants as the initial infection. ${ }^{18,19}$ The three samples that contained sequence variants novel to their readmission isolates (GR8, GR12, and GR22) comprise patterns most likely associated with reinfections. However, the novel bands in these samples could also represent an outgrowth of a minor parasite population that was originally undetected.

\section{DISCUSSION}

A critical variable in the evaluation of malaria treatment is the ability to differentiate new parasite infections from recrudescent infections. Efficacy studies of new and failing drugs rely on any combination of World Health Organization ${ }^{20}$ clinical standards and molecular genotyping methods, such as the nested PCR, ${ }^{21} \mathrm{RFLP}^{22}$ or $\mathrm{SSCP}^{23}$ for the classification of $P$. falciparum drug sensitivity. Although these techniques are frequently used, they are not without limitations. For example, the nested PCR and RFLP rely on electrophoretic migration of relatively small DNA fragments, which is only sensitive to changes in the size of the fragments. However, fragments with a similar number of nucleotides but with different sequences will migrate the same distance in these methods, leading to genotype misclassification. ${ }^{24} \mathrm{Un}$ like the nested PCR and RFLP, SSCP can detect single nucleotide differences, but it is technically demanding and is most effective when fragment sizes are less than 150 basepairs. $^{24}$ Finally, direct DNA sequencing can be used to detect sequence and size discrepant variants, but it is costly and unless complemented with cloning, ineffective at determining the number of sequence variants when multiple sequences are present. $^{5}$

In contrast to these techniques, the HTA method discussed herein is simple and can detect clustered nucleotide mismatches as well as size polymorphisms. Although the extent of mismatch clustering required for a mobility shift has not been empirically defined, a 5\% sequence divergence between HIV variants is the reported threshold of detection. ${ }^{13}$ Furthermore, studies on HIV have also shown that the HTA can detect a unique viral population comprising just $3-5 \%$ of the viral swarm. ${ }^{8,25}$ Another advantage of the HTA is that once a 


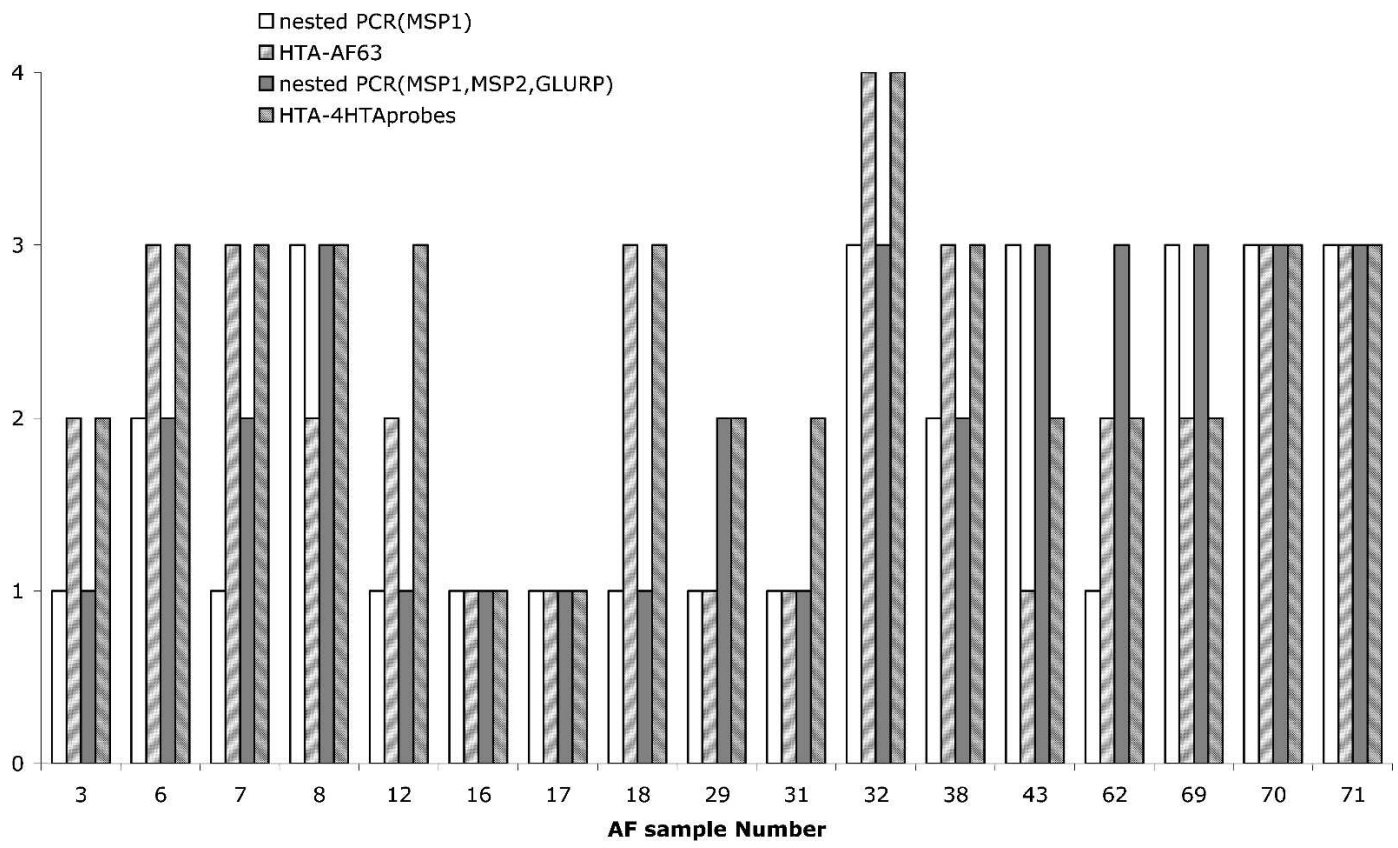

FIGURE 5. Plasmodium falciparum multiplicity of infection as determined by nested a polymerase chain reaction (PCR) or a heteroduplex tracking assay (HTA). The AF study numbers are listed below the groups of bars, and the number of sequence variants per isolate is listed by method. Open bars represent the P. falciparum merozoite surface protein 1 (PfMSP1) nested PCR, thin diagonal lines represent the AF63 HTA, gray boxes represent the PfMSP1, MSP2, and glutamate-rich protein (GLURP) nested PCRs, and thick diagonal lines represent HTA with all four probes.

probe is developed, analysis of genotype diversity is relatively rapid and large numbers of samples can be processed without difficulty. One potentially negative aspect of this assay is the use of radioactive nucleotides, which, although not evaluated in this study, could be substituted with fluorescent or biochemically modified nucleotides.

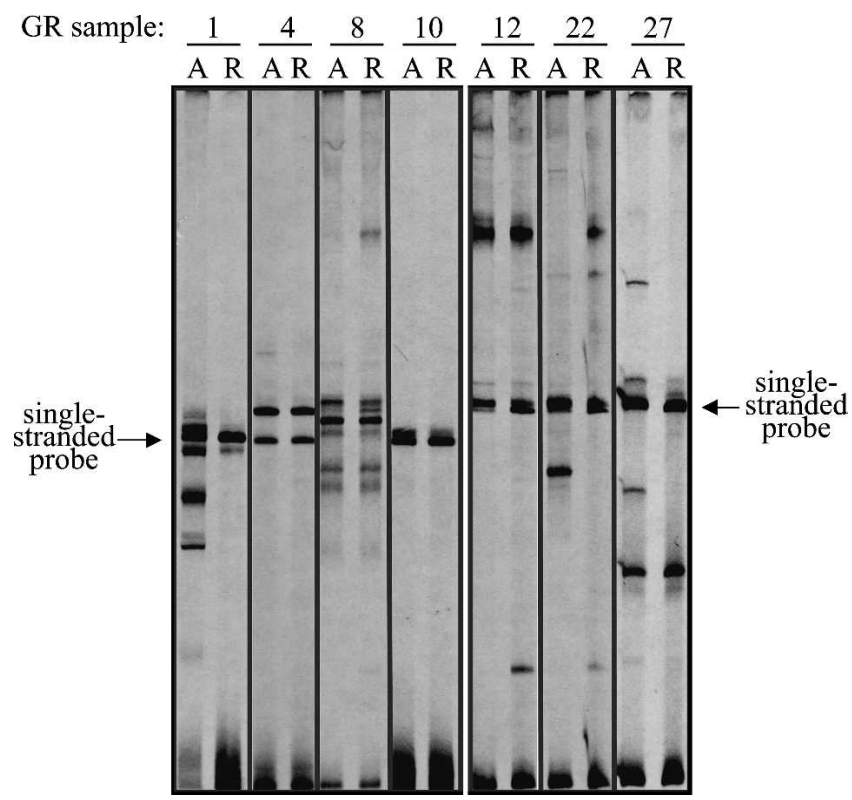

FigURE 6. Heteroduplex tracking assay autoradiograms of the AF63 probe annealed to seven paired primary and recurrent isolates from the GR study. A indicates samples taken at admission and $\mathrm{R}$ refers to samples taken from the same patient 7-42 days posttreatment as described in the Materials and Methods.
In general, when the degree of divergence between annealed sequences exceeds $4.5 \%$, the distance of heteroduplex migration is proportional to the degree of heterogeneity between the sequences. ${ }^{13}$ However, the AF63/MHP1452 heteroduplex, which is a complex of two $\mathrm{K} 1$ family members, migrates much more slowly than the AF63/AF22 heteroduplex, which comprises sequences of the $\mathrm{K} 1$ and MAD20 families. This unexpected migration is consistent with the observations of Upchurch and others, who showed that heterogeneity near the center of the heteroduplex influences migration more than heterogeneity near the ends, and that unpaired bases retard mobility more than mismatched bases. ${ }^{13}$ Indeed, pairwise alignment of AF63 with AF22 shows that AF 22 has a 9 basepair insertion 70 basepairs from the 5'end of the complex, as well as several nucleotide mismatches, while the AF63/MHP1452 heteroduplex has no basepair mismatches, but a large, 36-basepair insertion near the center of the heteroduplex (Figure 2B).

In a direct comparison by independent researchers masked to the results of the other assay, the HTA documented a greater amount of sequence diversity than the nested PCR. Furthermore, the HTA only required a single PCR amplification per sample, while the nested PCR requires three to six PCRs per sample, depending on the number of genes assayed. Even if the HTA and nested PCR gave identical results in terms of sequence diversity, the reduction in the number of PCRs per sample makes the HTA a more desirable method.

The DNA fingerprints of a parasite infection present at the time of admission compared with that of reappearing parasites are widely used to distinguish recrudescence from reinfection. ${ }^{5}$ Since malaria infections are frequently composed of multiple $P$. falciparum sequence variants at the time of admission, ${ }^{26,27}$ the HTA fingerprint will most likely contain more than one heteroduplex. However, once treatment has 
begun, drug-sensitive clones are eliminated, leaving only the drug-resistant clones. ${ }^{28}$ The appearance of new sequence variants could either represent a reinfection or an expansion of a minority sequence variant that was initially undetectable (see GR samples 8, 12, and 22 in Figure 6). In future studies, this problem can be addressed by collecting blood samples from patients on two consecutive days.

In summary, we describe the use of a PCR followed by the HTA to analyze block 2 of the MSP1 gene. The assay is simple, has a high resolution, and is sensitive enough to detect simultaneous, multifamily sequence variants in a patient isolate. These characteristics warrant the use of the PfMSP1 HTA in studies of anti-malarial drug efficacy.

Received May 28, 2004. Accepted for publication December 8, 2004. Acknowledgments: We thank Paul Wilson for technical support, Alisa Alker for helpful discussions, and the referees for their thorough review of this manuscript.

Financial support: This work was supported by National Institutes of Health (NIH) grants R23 AI054590 (Steven R. Meshnick), R01AI44667 (Ronald Swanstrom), T32 AI07151-26 (Jesse J. Kwiek), NIH Training Grant T32-AI07419 (Kimberly Ritola), and a scholarship from the Faculty of Medical Technology at Mahidol University under the Thai staff development project of the Ministry of University Affairs (Warunee Ngrenngarmlert). We also acknowledge the generous support of the University of North Carolina Center for AIDS Research (P30-AI50410).

Authors' addresses: Warunee Ngrenngarmlert and Wanida Ittarat, Department of Clinical Microscopy, Faculty of Medical Technology, Mahidol University, Bangkok 10700, Thailand, Telephone: 66-2-4197170, Fax: 66-2-412-4110. Jesse J. Kwiek and Steven R. Meshnick, Department of Microbiology and Immunology, CB\# 7290, University of North Carolina, Chapel Hill, NC 27599, Telephone: 919-843-4384, Fax: 919-962-8103, E-mail: meshnick@unc.edu. Deborah D. Kamwendo, Department of Epidemiology, University of Michigan School of Public Health, Ann Arbor, MI 48109. Kimberly Ritola and Ronald Swanstrom, Center for AIDS Research, University of North Carolina, Chapel Hill, NC 27599. Chansuda Wongsrichanalai and R. Scott Miller, Department of Immunology and Medicine, Armed Forces Research Institute of Medical Sciences, Bangkok, Thailand.

Reprint requests: Steven R. Meshnick, Department of Epidemiology, CB\# 7435, University of North Carolina, Chapel Hill, NC 27599.

\section{REFERENCES}

1. Tanabe K, Mackay M, Goman M, Scaife JG, 1987. Allelic dimorphism in a surface antigen gene of the malaria parasite Plasmodium falciparum. J Mol Biol 195: 273-287.

2. Ekala MT, Jouin H, Lekoulou F, Issifou S, Mercereau-Puijalon $\mathrm{O}$, Ntoumi F, 2002. Plasmodium falciparum merozoite surface protein 1 (MSP1): genotyping and humoral responses to allelespecific variants. Acta Trop 81: 33-46.

3. Miller LH, Roberts T, Shahabuddin M, McCutchan TF, 1993. Analysis of sequence diversity in the Plasmodium falciparum merozoite surface protein-1 (MSP-1). Mol Biochem Parasitol 59: $1-14$.

4. Hoffmann EH, Ribolla PE, Ferreira MU, 2003. Genetic relatedness of Plasmodium falciparum isolates and the origin of allelic diversity at the merozoite surface protein-1 (MSP-1) locus in Brazil and Vietnam. Malar J 2: 24.

5. Snounou G, Beck H-P, 1998. The Use of PCR genotyping in the assessment of recrudescence or reinfection after antimalarial drug treatment. Parasitol Today 14: 462-467.

6. Farnert A, Arez AP, Babiker HA, Beck HP, Benito A, Bjorkman A, Bruce MC, Conway DJ, Day KP, Henning L, MercereauPuijalon O, Ranford-Cartwright LC, Rubio JM, Snounou G, Walliker D, Zwetyenga J, do Rosario VE, 2001. Genotyping of Plasmodium falciparum infections by PCR: a comparative multicentre study. Trans $R$ Soc Trop Med Hyg 95: 225-232.
7. Delwart EL, Sheppard HW, Walker BD, Goudsmit J, Mullins JI, 1994. Human immunodeficiency virus type 1 evolution in vivo tracked by DNA heteroduplex mobility assays. $J$ Virol 68 : 6672-6683.

8. Kitrinos KM, Hoffman NG, Nelson JA, Swanstrom R, 2003. Turnover of env variable region 1 and 2 genotypes in subjects with late-stage human immunodeficiency virus type 1 infection. J Virol 77: 6811-6822.

9. Sitki-Green D, Edwards RH, Webster-Cyriaque J, Raab-Traub $\mathrm{N}, 2002$. Identification of Epstein-Barr virus strain variants in hairy leukoplakia and peripheral blood by use of a heteroduplex tracking assay. $J$ Virol 76: 9645-9656.

10. Pickard AL, Wongsrichanalai C, Purfield A, Kamwendo D, Emery K, Zalewski C, Kawamoto F, Miller RS, Meshnick SR, 2003. Resistance to antimalarials in Southeast Asia and genetic polymorphisms in pfmdr1. Antimicrob Agents Chemother 47: 2418-2423.

11. Mwapasa V, Rogerson SJ, Molyneux ME, Abrams ET, Kamwendo DD, Lema VM, Tadesse E, Chaluluka E, Wilson PE, Meshnick SR, 2004. The effect of Plasmodium falciparum malaria on peripheral and placental HIV-1 RNA concentrations in pregnant Malawian women. AIDS 18: 1051-1059.

12. Kimura M, Kaneko O, Inoue A, Ishii A, Tanabe K, 1995. Amplification by polymerase chain reaction of Plasmodium falciparum DNA from Giemsa-stained thin blood smears. Mol Biochem Parasitol 70: 193-197.

13. Upchurch DA, Shankarappa R, Mullins JI, 2000. Position and degree of mismatches and the mobility of DNA heteroduplexes. Nucleic Acids Res 28: E69.

14. Kamwendo DD, Dzinjalamala FK, Snounou G, Kanjala MC, Mhango CG, Molyneux ME, Rogerson SJ, 2002. Plasmodium falciparum: PCR detection and genotyping of isolates from peripheral, placental, and cord blood of pregnant Malawian women and their infants. Trans $R$ Soc Trop Med Hyg 96: 145149.

15. Snounou G, Viriyakosol S, Zhu XP, Jarra W, Pinheiro L, do Rosario VE, Thaithong S, Brown KN, 1993. High sensitivity of detection of human malaria parasites by the use of nested polymerase chain reaction. Mol Biochem Parasitol 61: 315320.

16. Hartl DL, Volkman SK, Nielsen KM, Barry AE, Day KP, Wirth DF, Winzeler EA, 2002. The paradoxical population genetics of Plasmodium falciparum. Trends Parasitol 18: 266-272.

17. Kimura E, Mattei D, di Santi SM, Scherf A, 1990. Genetic diversity in the major merozoite surface antigen of Plasmodium falciparum: high prevalence of a third polymorphic form detected in strains derived from malaria patients. Gene 91: 57-62.

18. Cattamanchi A, Kyabayinze D, Hubbard A, Rosenthal PJ, Dorsey G, 2003. Distinguishing recrudescence from reinfection in a longitudinal antimalarial drug efficacy study: comparison of results based on genotyping of msp-1, msp-2, and glurp. Am J Trop Med Hyg 68: 133-139.

19. Brockman A, Paul RE, Anderson TJ, Hackford I, Phaiphun L, Looareesuwan S, Nosten F, Day KP, 1999. Application of genetic markers to the identification of recrudescent Plasmodium falciparum infections on the northwestern border of Thailand. Am J Trop Med Hyg 60: 14-21.

20. World Health Organization, 1996. Assessment of Therapeutic Efficacy of Antimalarial Drugs for Uncomplicated Falciparum Malaria in Areas with Intense Transmission. Geneva: World Health Organization.

21. Snounou G, Singh B, 2002. Nested PCR analysis of Plasmodium parasites. Methods Mol Med 72: 189-203.

22. Ohrt C, Mirabelli-Primdahl L, Karnasuta C, Chantakulkij S, Kain KC, 1997. Distinguishing Plasmodium falciparum treatment failures from reinfections by restrictions fragment length polymorphism and polymerase chain reaction genotyping. Am J Trop Med Hyg 57: 430-437.

23. Kain KC, Craig AA, Ohrt C, 1996. Single-strand conformational polymorphism analysis differentiates Plasmodium falciparum treatment failures from re-infections. Mol Biochem Parasitol 79: $167-175$.

24. Gasser RB, 1997. Mutation scanning methods for the analysis of parasite genes. Int J Parasitol 27: 1449-1463.

25. Resch W, Parkin N, Stuelke EL, Watkins T, Swanstrom R, 2001. 
A multiple-site-specific heteroduplex tracking assay as a tool for the study of viral population dynamics. Proc Natl Acad Sci U S A 98: 176-181.

26. Snewin VA, Herrera M, Sanchez G, Scherf A, Langsley G, Herrera S, 1991. Polymorphism of the alleles of the merozoite surface antigens MSA1 and MSA2 in Plasmodium falciparum wild isolates from Colombia. Mol Biochem Parasitol 49: 265275 .
27. Daubersies P, Sallenave-Sales S, Magne S, Trape JF, Contamin H, Fandeur T, Rogier C, Mercereau-Puijalon O, Druilhe P, 1996. Rapid turnover of Plasmodium falciparum populations in asymptomatic individuals living in a high transmission area. Am J Trop Med Hyg 54: 18-26.

28. Jafari S, Le Bras J, Bouchaud O, Durand R, 2004. Plasmodium falciparum clonal population dynamics during malaria treatment. J Infect Dis 189: 195-203. 